\title{
CAPINA E ADUBAÇÃO NITROGENADA EM COBERTURA REALIZADA EM DIFERENTES ESTÁDIOS DE DESENVOLVIMENTO DO FEIJOEIRO. CULTIVO DE "INVERNO"
}

\author{
WEEDING AND SIDE-DRESSING OF NITROGEN FERTILIZER REALIZED ON \\ DIFFERENT BEAN DEVELOPMENT STAGES. III - "WINTER" CROP SEASON
}

\author{
José Mauro Valente Paes ${ }^{1}$ Antônio Américo Cardoso² \\ Antônio Alberto da Silva ${ }^{3}$ Césio Humberto de Brito ${ }^{4}$
}

\section{RESUMO}

O objetivo deste trabalho foi avaliar os efeitos da adubação nitrogenada em cobertura após a capina, realizada em diferentes épocas na cultura do feijão (Phaseolus vulgaris L.), de três tipos de hábito de crescimento, no cultivo de "inverno". O estudo foi feito durante dois anos, utilizando-se três cultivares, no primeiro ano: Novo Jalo (tipo I), Ouro (tipo II) e Ouro Negro (tipo III) e dois, no segundo ano: Ouro e Ouro Negro. Cada cultivar constituiu um experimento. Os tratamentos foram constituídos por seis épocas de capina, duas doses de nitrogênio em cobertura, tendo como fonte o sulfato de amônio, e dois tratamentos adicionais, dispostos em blocos casualizados, em esquema fatorial $\left(\begin{array}{lll}6 & x & 2\end{array}\right)+2$, com quatro repetições. Na testemunha com capina e na testemunha sem capina, o nitrogênio foi distribuído no estádio $V_{3}$. A competição com plantas daninhas durante todo o ciclo da cultura causou redução em todos os componentes primários de produção do 'Ouro Negro', apenas no número de grãos por vagem do 'Novo Jalo' e na massa de 100 grãos do 'Ouro'. Nos três cultivares, o nitrogênio em cobertura promoveu aumentos no rendimento de grãos e do número de vagens por hectare e somente não aumentou a massa de 100 grã̃s no 'Novo Jalo'. O nitrogênio aplicado em cobertura imediatamente após a capina, realizada com atraso de dez dias, em relação ao período total de prevenção de interferência, proporcionou recuperação total da capacidade produtiva dos feijoeiros.

Palavras-chave: Phaseolus vulgaris, planta daninha, nitrogênio.

\section{SUMMARY}

During two years, it was evaluated the effects of side-dressing application of nitrogen after weeding made at different growth periods of the bean crop (Phaseolus vulgaris L.) during the winter season. Three cultivars were used in the first year [Novo Jalo (type I), Ouro (type II) and Ouro Negro (type III)] and two in the second year (Ouro and Ouro Negro). Each cultivar constituted one experiment. The treatments consisted of six weeding periods, two side-dressing applications of nitrogen $(0$ and 30/ha), with ammonium sulphate as source, and two additional treatments. Treatments were arranged in a $\left(\begin{array}{lll}6 & \times & 2\end{array}\right)+2$ factorial randomized block experimental design, with four replications. In The control treatments plus weeding and control treatment without weeding, the nitrogen fertilizer was distributed at $V_{3}$ stage. Competition against weeds throughout the whole cycle of the cultivars caused a reduction in all primary components of 'Ouro Negro' and only for the number grains per pod of 'Novo Jalo' and for the weight of 100 grains of 'Ouro'. Side-dressing application of nitron fertilizer increased grain yield for all three cultivars as well as the number of pods per hectare but the weight of 100 grains did not increase for 'Novo Jalo'. When side-dressing nitrogen application was done immediately after delaing weeding for 10 days, in relation to the total period of interference prevention, was not able to provide crop yield recovery capacity.

Key words: Phaseolus vulgaris, weed, nitrogen.

\section{INTRODUÇÃO}

O plantio de feijão na terceira época, normalmente realizado entre abril e junho ou, por vezes, mais tarde, é denominado cultivo de "inverno" na Zona da Mata de Minas Gerais. Tanto nas áreas tradicionalmente produtoras como em outras

\footnotetext{
${ }^{1}$ Engenheiro Agrônomo, DS, Pesquisador EPAMIG/CTTP, CP 351, 38001-970, Uberaba, MG. Autor para correspondência.

${ }^{2}$ Engenheiro Agrônomo, DS, Professor Titular do Departamento de Fitotecnia, Universidade Federal de Viçosa (UFV), Viçosa, MG.

${ }^{3}$ Engenheiro Agrônomo, DS, Professor Adjunto do Departamento de Fitotecnia , UFV.

${ }^{4}$ Engenheiro Agrônomo, DS, Professor Visitante do Departamento de Agronomia, Universidade Federal de Uberlândia (UFU), Uberlândia, MG.
} 
áreas, tem contribuído para incrementar a cultura no Brasil, principalmente em termos de produtividade, que em 1994 foi de 1311/ha (INSTITUTO BRASILEIRO DE GEOGRAFIA E ESTATÍSTICA, 1995). No cultivo de inverno em Minas Gerais, é indispensável a utilização de irrigação, e a exploração da cultura também demanda maiores investimentos. Essa época de plantio ajuda na estabilização da oferta de feijão, minimizando a necessidade de importação do produto de outros estados (MOURA et al., 1994).

CALVACHE et al. (1995) verificaram que o bom manejo da irrigação foi condição necessária para resposta à utilização de $80 \mathrm{de} \mathrm{N} / \mathrm{ha}$, dose que proporcionou produtividade de 3015/ha. Observaram, ainda, que não houve resposta à aplicação desse nutriente, quando fizeram restrição de água no período de florescimento. Outro problema do plantio no cultivo de inverno é a carência de informações técnicas quanto ao manejo de plantas daninhas (FERREIRA et al., 1994), pois o conhecimento dos períodos de interferência das plantas daninhas nas plantas cultivadas permite que o estabelecimento de medidas de controle seja eficiente no sentido de minimizar os efeitos prejudiciais da competição.

Diversos são os fatores que podem influenciar a resposta da cultura do feijão ao nitrogênio, sendo um destes a presença de plantas daninhas. Normalmente, existe um período, a partir da semeadura ou emergência, em que a cultura pode conviver com a comunidade infestante, antes que a interferência se instale de maneira definitiva e reduza significativamente a produtividade da lavoura, chamado por PITELLI \& DURIGAN (1984) de período anterior à interferência. Seu limite superior retrata a época em que a interferência compromete irreversivelmente a produtividade econômica da cultura. A aplicação de certas práticas culturais contribui para a diminuição deste período. Teoricamente, o final desse período seria a época ideal para o primeiro controle das plantas invasoras, mas, na prática, geralmente este período não pode ser considerado, pois a cultura e, ou plantas daninhas podem ter atingido tal estádio de desenvolvimento que inviabilize o uso de práticas mecânicas ou controle químico (PITELLI, 1985).

Quando se atrasa o início da capina, ocorre competição entre a cultura e as plantas daninhas pelos fatores de produção, havendo redução da produtividade de grãos de feijão (NIETO et $\boldsymbol{a l}$. , 1968; VIEIRA, 1970). Este trabalho objetivou avaliar os efeitos da adubação nitrogenada em cobertura efetuada após a capina, realizada em diferentes épocas na cultura do feijão (Phaseolus vulgaris L.), de três tipos de hábito de crescimento, no cultivo de "inverno".

\section{MATERIAL E MÉTODOS}

Foram instalados três experimentos, na segunda quinzena de maio de 1994: 'Novo Jalo' (tipo I - hábito de crescimento determinado); 'Ouro' (tipo II - hábito de crescimento indeterminado arbustivo, com ramificação ereta e fechada); e, 'Ouro Negro' (tipo III - hábito de crescimento indeterminado prostrado, com ramificação aberta); e dois, na primeira quinzena de junho de 1995: 'Ouro' e 'Ouro Negro', em solo Podzólico vermelho-amarelo câmbico, fase terraço, no município de Coimbra-MG. Cada cultivar constituiu um experimento. Na camada de $0-20 \mathrm{~cm}$ de profundidade, a amostra do solo apresentou as seguintes características químicas: $\mathrm{pH}$ em $\mathrm{H}_{2} \mathrm{O} 5,3, \mathrm{P}=5,1 \mathrm{mg} / \mathrm{dm}^{3}, \mathrm{~K}=53 \mathrm{mg} / \mathrm{dm}^{3}, \mathrm{Ca}=1,6$ $\mathrm{cmol}_{\mathrm{c}} / \mathrm{dm}^{3}, \mathrm{Mg}=0,6 \mathrm{cmol}_{\mathrm{c}} / \mathrm{dm}^{3}, \mathrm{Al}=0,1 \mathrm{cmol}_{\mathrm{c}} / \mathrm{dm}^{3} ; \mathrm{e}$ texturais: areia $=19 \%$, silte $=17 \%$ e argila $=64 \%$, sendo o solo classificado como muito argiloso.

Os tratamentos foram dispostos em blocos casualizados, em esquema fatorial $(6 \times 2)+2$, correspondendo a seis épocas de capina (estádios de desenvolvimento $\mathrm{V}_{3}, \mathrm{~V}_{3}+5, \mathrm{~V}_{3}+10, \mathrm{~V}_{3}+15, \mathrm{~V}_{3}+$ 20 e $V_{3}+25$ dias), duas doses de nitrogênio em cobertura (0 e 30/ha) e dois tratamentos adicionais (testemunha com capina (TCC) e testemunha sem capina (TSC)), com quatro repetições. A dose de 30/ha de N, tendo como fonte o sulfato de amônio, e a adubação no sulco de plantio foram feitas com base nos resultados da análise química do solo e seguindo as recomendações da COMISSÃO DE FERTILIDADE DO SOLO DO ESTADO DE MINAS GERAIS (1989), aplicando-se o equivalente a 650/ha da fórmula 4-14-8. Esse nutriente foi distribuído em cobertura imediatamente após cada época de capina, sendo também aplicado nos tratamentos adicionais no estádio de desenvolvimento $\mathrm{V}_{3}$. A TCC foi mantida livre das plantas daninhas até o estádio de desenvolvimento $\mathrm{V}_{3}+25$ dias, por meio de três capinas, realizadas aos 15, 25 e 40 dias, após a emergência das plântulas de feijão (estádio $\mathrm{V}_{1}$ ), que foi observada em torno de seis dias, após a semeadura. Nesse estádio, foi avaliado o estande inicial por metro (EIM). A primeira época de capina teve como referência o estádio de desenvolvimento $V_{3}$ dos cultivares de feijão (15 dias após emergência), quando a primeira folha trifoliolada de $50 \%$ das plantas estava totalmente aberta.

As plantas daninhas presentes na área do experimento foram: losna-brava (Artemisia verlotorum), mentrasto (Ageratum conyzoides), corda-de-viola (Ipomoea grandifolia), trevo (Oxalis oxyptera), tiririca (Cyperus rotundus) e grama-seda (Cynodon dactylon). Antes de cada capina, foi feito o levantamento da infestação de plantas daninhas, 
avaliando-se visualmente a percentagem de cobertura real da comunidade infestante $\mathrm{e} a$ percentagem de cobertura real de plantas daninhas, por espécie botânica, presentes em cada parcela experimental. Esta foi composta por quatro linhas de $7,5 \mathrm{~m}$ de comprimento, espaçadas de $0,5 \mathrm{~m}$ e com aproximadamente 15 sementes por metro. A área útil da parcela compreendeu os $4 \mathrm{~m}^{2}$ centrais.

Nos dois anos, o ponto de colheita foi observado em torno de 105 dias após o plantio. Foram avaliados o estande final por metro (EFM), o rendimento de grãos (RG), em kg/ha, o número de vagens por hectare (NVHA), o número de grãos por vagem (NGV) e a massa de 100 grãos (M100G), em gramas.

Após a colheita do feijão, fez-se, por amostragem, a coleta das plantas daninhas remanescentes, utilizando-se um quadrado de ferro $\left(0,25 \mathrm{~m}^{2}\right)$, que foi jogado ao acaso, por duas vezes, em cada parcela experimental. As plantas daninhas foram separadas em monocotiledôneas e dicotiledôneas e colocadas em estufa de circulação de ar forçado a $72^{\circ} \mathrm{C}$. Após atingirem massa constante, utilizou-se uma balança para a determinação da massa seca.

Inicialmente, foram realizadas as análises de variância de todas as características avaliadas para cada cultivar, em cada ano de plantio, isoladamente. Posteriormente, efetuou-se a análise de variância conjunta, por cultivar, das características em que os quadrados médios residuais não ultrapassaram uma relação aproximada de 7:1, conforme recomendam BANZATTO \& KRONKA (1989). Na análise de variância conjunta, foram considerados os efeitos de blocos e anos aleatórios e o efeito de tratamentos fixos. O teste de F, desses efeitos, está apresentado na tabela 1 e foram testados de acordo com o que preconizam CRUZ \& REGAZZI (1994).

\section{RESULTADOS E DISCUS- SÃO}

Verificou-se redução significativa do RG da TSC, em relação à TCC, nos cultivares Ouro e Ouro Negro (tabela 2). A competição de plantas daninhas reduziu a produtividade desses cultivares em 27 e 34\%, respectivamente. Essa competição causou redução em todos os componentes de produção do 'Ouro Negro' e apenas no
NGV, do 'Novo Jalo', e na M100G, do 'Ouro'. Esses resultados estão de acordo com NIETO $\boldsymbol{e t}$ al. (1968) e VIEIRA (1970) que verificaram redução na produtividade de grãos de feijão quando ocorre competição entre a cultura e as plantas daninhas pelos fatores de produção.

Observa-se na tabela 2 que, nos tratamentos em que foram feitas capinas e não se utilizou nitrogênio em cobertura, as médias do RG do 'Ouro' e 'Ouro Negro' e da M100G do 'Ouro' foram significativamente inferiores em relação à da TCC, o que evidencia o efeito de competição de plantas daninhas sobre os feijoeiros. Entretanto, nesses cultivares, a aplicação de nitrogênio em cobertura após as diferentes épocas de capina, inclusive no estádio $\mathrm{V}_{3}+$ $25 \mathrm{~N}_{1}$, promoveu recuperação das plantas de feijão e, conseqüientemente, não ocorreu redução significativa no rendimento de grãos, desses tratamentos, em relação à TCC. A possível explicação para essa recuperação é que esses cultivares, por serem de hábito de crescimento indeterminado (tipo II e III) e, talvez, mais tolerantes a baixas temperaturas, promoveram maior cobertura do solo, diminuindo a interferência de plantas daninhas. Por isso, provavelmente, tiveram melhor aproveitamento do nitrogênio aplicado em cobertura, fornecendo-lhe maior capacidade de recuperação dos danos provocados por essas invasoras. Segundo MARSCHNER (1986), o nitrogênio é fundamental para o crescimento e desenvolvimento de todas as plantas cultivadas, que o requerem em grandes quantidades, sendo constituinte obrigatório de aminoácidos, proteínas e ácidos nucléicos; participa, direta ou indire-
Tabela 1 - Esquema de uma análise de variância conjunta mostrando como se calculam os valores de $\mathrm{F}$, em que os efeitos de blocos e anos foram considerados aleatórios e o efeito de tratamento fixo.

\begin{tabular}{|c|c|c|c|}
\hline Fontes de Variação & GL & Quadrados Médios & $\mathrm{F}$ \\
\hline $\operatorname{Blocos}(\mathrm{B}) / \operatorname{Anos}(\mathrm{A})$ & 6 & $\mathrm{QM}(\mathrm{B} / \mathrm{A})$ & $\mathrm{QM}(\mathrm{B} / \mathrm{A}) / \mathrm{QM}(\mathrm{RM})$ \\
\hline $\operatorname{Anos}(\mathrm{A})$ & 1 & QM(a) & $\mathrm{QM}(\mathrm{A}) / \mathrm{QM}(\mathrm{B} / \mathrm{A})$ \\
\hline Tratamentos (TR) & (13) & QM(TR) & $\mathrm{QM}(\mathrm{TR}) / \mathrm{QM}(\mathrm{A} \times \mathrm{TR})$ \\
\hline Èpocas de Capina (EC) & 5 & $\mathrm{QM}(\mathrm{EC})$ & $\mathrm{QM}(\mathrm{EC}) / \mathrm{QM}(\mathrm{A} \times \mathrm{TR})$ \\
\hline Doses de Nitrogênio (N) & 1 & $\mathrm{QM}(\mathrm{N})$ & $\mathrm{QM}(\mathrm{N}) / \mathrm{QM}(\mathrm{A} \times \mathrm{TR})$ \\
\hline $\mathrm{EC} \times \mathrm{N}$ & 5 & $\mathrm{QM}(\mathrm{EC} \times \mathrm{N})$ & $\mathrm{QM}(\mathrm{EC} \times \mathrm{N}) / \mathrm{QM}(\mathrm{A} \times \mathrm{TR})$ \\
\hline Testemunhas $(\mathrm{T})$ & 1 & $\mathrm{QM}(\mathrm{T})$ & $\mathrm{QM}(\mathrm{T}) / \mathrm{QM}(\mathrm{A} \times \mathrm{TR})$ \\
\hline T vs Fatorial (FAT) & 1 & QM(T vs FAT) & $\mathrm{QM}(\mathrm{T}$ vs FAT $) / \mathrm{QM}(\mathrm{A} \times \mathrm{TR})$ \\
\hline A $x$ TR & (13) & $\mathrm{QM}(\mathrm{A} \times \mathrm{TR})$ & $\mathrm{QM}(\mathrm{A} \times \mathrm{TR}) / \mathrm{QM}(\mathrm{RM})$ \\
\hline A $x$ EC & 5 & $\mathrm{QM}(\mathrm{A} \times \mathrm{EC})$ & $\mathrm{QM}(\mathrm{A} \times \mathrm{EC}) / \mathrm{QM}(\mathrm{RM})$ \\
\hline $\mathrm{A} \times \mathrm{N}$ & 1 & $\mathrm{QM}(\mathrm{A} \times \mathrm{N})$ & $\mathrm{QM}(\mathrm{A} \times \mathrm{N}) / \mathrm{QM}(\mathrm{RM})$ \\
\hline A X EC x N & 5 & $\mathrm{QM}(\mathrm{A} \times \mathrm{EC} \times \mathrm{N})$ & $\mathrm{QM}(\mathrm{A} \times \mathrm{EC} \times \mathrm{N}) / \mathrm{QM}(\mathrm{RM})$ \\
\hline $\mathrm{A} \times \mathrm{T}$ & 1 & $\mathrm{QM}(\mathrm{A} \times \mathrm{T})$ & $\mathrm{QM}(\mathrm{A} \times \mathrm{T}) / \mathrm{QM}(\mathrm{RM})$ \\
\hline A $x$ T vs FAT & 1 & QM(A x T vs FAT) & $\mathrm{QM}(\mathrm{A} \times \mathrm{T}$ vs FAT $) / \mathrm{QM}(\mathrm{RM})$ \\
\hline Resíduo Médio (RM) & 78 & $\mathrm{QM}(\mathrm{RM})$ & \\
\hline
\end{tabular}


Tabela 2 - Valores médios de rendimento de grãos (RG), em kg/ha, do número de vagens por hectare (NVHA), do número de grãos por vagem (NGV) e da massa de 100 grãos (M100G), em g, do 'Novo Jalo', 'Ouro' e 'Ouro Negro', em cada tratamento, no cultivo de "inverno"

\begin{tabular}{|c|c|c|c|c|c|c|c|c|c|c|c|c|}
\hline \multirow[t]{2}{*}{ Tratamentos } & \multicolumn{4}{|c|}{ 'Novo Jalo' } & \multicolumn{4}{|c|}{ 'Ouro' } & \multicolumn{4}{|c|}{ 'Ouro Negro' } \\
\hline & RG & $\begin{array}{c}\text { NVHA } \\
\times 10^{3}\end{array}$ & NGV & $\begin{array}{c}\text { M100 } \\
\text { G }\end{array}$ & RG & $\begin{array}{c}\text { NVHA } \\
\times 10^{3}\end{array}$ & NGV & M100G & RG & $\begin{array}{c}\text { NVHA } \\
\times 10^{3}\end{array}$ & NGV & M100G \\
\hline $\mathrm{V}_{3} \mathrm{~N}_{0}$ & 714 & 843 & 2,4 & 33,5 & $1085^{1^{\prime}}$ & 1915 & 3,5 & $15,7^{1 /}$ & $827^{1^{\prime}}$ & 1451 & $3,3^{1^{\prime}}$ & 16,8 \\
\hline $\mathrm{V}_{3}+5 \mathrm{~N}_{0}$ & 669 & 649 & 2,7 & 34,8 & $1122^{1^{\prime}}$ & 2096 & 3,4 & $15,8^{1 /}$ & $785^{1^{\prime \prime}}$ & $1393^{1^{\prime}}$ & $3,3^{1 /}$ & 16,4 \\
\hline $\mathrm{V}_{3}+10 \mathrm{~N}_{0}$ & 530 & 628 & 2,3 & 34,8 & $1034^{\frac{1 /}{}}$ & 1849 & 3,5 & $16,0^{1 /}$ & $902^{1^{\prime}}$ & 1549 & $3,3^{1^{\prime}}$ & 16,7 \\
\hline $\mathrm{V}_{3}+15 \mathrm{~N}_{0}$ & 431 & 478 & 2,4 & 37,5 & $1099^{1 /}$ & 1921 & 3,5 & $16,1^{1 /}$ & $765^{1^{\prime}}$ & 1414 & $3,0^{1 /}$ & 16,8 \\
\hline $\mathrm{V}_{3}+20 \mathrm{~N}_{0}$ & 488 & 546 & 2,4 & 33,9 & $1052^{\frac{1}{\prime}}$ & 1967 & 3,5 & $15,1^{1 /}$ & $815^{1^{\prime}}$ & 1464 & 3,4 & $16,1^{1 /}$ \\
\hline $\mathrm{V}_{3}+25 \mathrm{~N}_{0}$ & 669 & 656 & 2,8 & 34,5 & $959^{1^{\prime}}$ & $1712^{1^{\prime}}$ & 3,5 & $16,1^{1 /}$ & $716^{1 /}$ & $1212^{1 /}$ & 3,5 & $16,1^{1 /}$ \\
\hline $\mathrm{V}_{3} \mathrm{~N}_{1}$ & 793 & 859 & 2,8 & 32,6 & 1665 & 2694 & 3,5 & 17,5 & 1191 & 2001 & 3,4 & 17,0 \\
\hline $\mathrm{V}_{3}+5 \mathrm{~N}_{1}$ & 1006 & 1052 & 2,9 & 33,2 & 1375 & 2340 & 3,2 & 17,8 & 1150 & 1894 & 3,4 & 17,0 \\
\hline $\mathrm{V}_{3}+10 \mathrm{~N}_{1}$ & 781 & 799 & 2,9 & 33,6 & 1482 & 2414 & 3,6 & 17,1 & 1119 & 1905 & 3,4 & 16,7 \\
\hline $\mathrm{V}_{3}+15 \mathrm{~N}_{1}$ & 648 & 601 & 2,9 & 35,5 & 1384 & 2289 & 3,7 & 16,6 & 1255 & 2024 & 3,5 & 17,1 \\
\hline $\mathrm{V}_{3}+20 \mathrm{~N}_{1}$ & 1091 & 1081 & 2,9 & 34,9 & 1622 & 2699 & 3,5 & 17,0 & 1181 & 1953 & 3,4 & 17,1 \\
\hline $\mathrm{V}_{3}+25 \mathrm{~N}_{1}$ & 673 & 667 & 2,8 & 36,1 & 1319 & 2350 & 3,3 & 16,2 & 1320 & 2128 & 3,6 & 16,8 \\
\hline Test. c/ capina & $823 \mathrm{~A}^{\mathrm{2}^{2 l}}$ & $794 \mathrm{~A}$ & $2,8 \mathrm{~A}$ & $36,7 \mathrm{~A}$ & $1617 \mathrm{~A}$ & $2647 \mathrm{~A}$ & $3,6 \mathrm{~A}$ & $16,8 \mathrm{~A}$ & $1315 \mathrm{~A}$ & 2045 A & $3,7 \mathrm{~A}$ & $17,1 \mathrm{~A}$ \\
\hline Test. s/ capina & $559 \mathrm{~A}$ & $660 \mathrm{~A}$ & $2,4 \mathrm{~B}$ & $33,3 \mathrm{~A}$ & $1184 \mathrm{~B}$ & $2150 \mathrm{~A}$ & $3,4 \mathrm{~A}$ & $15,4 \mathrm{~A}$ & $862 \mathrm{~B}$ & $1540 \mathrm{~B}$ & $3,2 \mathrm{~B}$ & $16,4 \mathrm{~B}$ \\
\hline CV (\%) & 30,50 & 25,90 & 10,4 & 7,8 & 22,9 & 19,3 & 9,5 & 7,7 & 29,7 & 24,9 & 9,0 & 6,7 \\
\hline
\end{tabular}

1/ Diferem significativamente da testemunha com capina, pelo teste de Dunnett, a 5\% de probabilidade.

2'Médias seguidas pela mesma letra não diferem significativamente, pelo teste $\mathrm{F}$, a $5 \%$ de probabilidade.

$\mathrm{V}_{3}=$ Estádio de desenvolvimento dos cultivares de feijão (15 dias após emergência), quando a primeira folha trifoliolada de $50 \%$ das plantas estava totalmente aberta.

$\mathrm{N}_{0}=0 \mathrm{~kg} / \mathrm{ha}$ de $\mathrm{N}$ em cobertura

$\mathrm{N}_{1}=30 \mathrm{~kg} / \mathrm{ha}$ de $\mathrm{N}$ distribuído em cobertura imediatamente após cada época de capina.

tamente, de inúmeros processos bioquímicos e faz parte da molécula de clorofila, sendo, portanto, indispensável à sua síntese.

Observa-se na tabela 3 que a adubação nitrogenada em cobertura aumentou o RG, o NVHA e o NGV do 'Novo Jalo'; a M100G do 'Ouro' e 'Ouro Negro'; e o NGV do 'Ouro Negro', mas não teve influência na M100G do 'Novo Jalo' e no NGV do 'Ouro'. O nitrogênio em cobertura promoveu aumento da RG e do NVHA dos cultivares 'Ouro' e 'Ouro Negro', nos dois anos. No segundo ano, a aplicação de nitrogênio em cobertura promoveu aumento no RG do 'Ouro', e, na presença ou ausência desse nutriente em cobertura, verificou-se tendência de valores superiores da RG e do NVHA do 'Ouro Negro' (tabela 4). Esses resultados estão de acordo com AMANE (1994) e DINIZ et al. (1995) que obtiveram aumentos significativos na produtividade de grãos e na massa de 100 grãos, quando utilizaram 30 de N/ha em cobertura. DINIZ et al. (1995) verificaram ainda aumento no número de vagens por planta, mas não detectaram influência do nutriente no número médio de grãos por vagem.

Em nenhum cultivar se detectou influência significativa nos componentes de rendimento e,
Tabela 3 - Valores médios de rendimento de grãos (RG), do número de vagens por hectare (NVHA), do número de grãos por vagem (NGV) e da massa de 100 grãos (M100G) do 'Novo Jalo', 'Ouro' e 'Ouro Negro', em cada dose de nitrogênio distribuído em cobertura, no cultivo de "inverno".

\begin{tabular}{|c|c|c|c|c|}
\hline $\begin{array}{l}\text { Doses de } \\
\mathrm{N}(\mathrm{kg} / \mathrm{ha})\end{array}$ & $\mathrm{RG}$ (kg/ha) & $\begin{array}{c}\text { NVHA } x \\
10^{3}\end{array}$ & NGV & M100G (g) \\
\hline & \multicolumn{4}{|c|}{ 'Novo Jalo' } \\
\hline \multirow{3}{*}{$\begin{array}{l}0 \\
30\end{array}$} & $583 \mathrm{~B}$ & $633 \mathrm{~B}$ & $2,51 \mathrm{~B}$ & $34,84 \mathrm{~A}$ \\
\hline & $832 \mathrm{~A}$ & $843 \mathrm{~A}$ & $2,85 \mathrm{~A}$ & $34,32 \mathrm{~A}$ \\
\hline & \multicolumn{4}{|c|}{ 'Ouro' } \\
\hline \multirow{3}{*}{$\begin{array}{l}0 \\
30\end{array}$} & 1059 & 1910 & $3,47 \mathrm{~A}$ & $15,81 \mathrm{~B}$ \\
\hline & 1474 & 2464 & $3,47 \mathrm{~A}$ & $17,04 \mathrm{~A}$ \\
\hline & \multicolumn{4}{|c|}{ 'Ouro Negro' } \\
\hline 0 & 803 & 1414 & $3,29 \mathrm{~B}$ & $16,49 \mathrm{~B}$ \\
\hline 30 & 1203 & 1984 & $3,46 \mathrm{~A}$ & $16,94 \mathrm{~A}$ \\
\hline
\end{tabular}

Médias não seguidas pela mesma letra diferem significativamente, pelo teste $\mathrm{F}$, a $5 \%$ de probabilidade. 


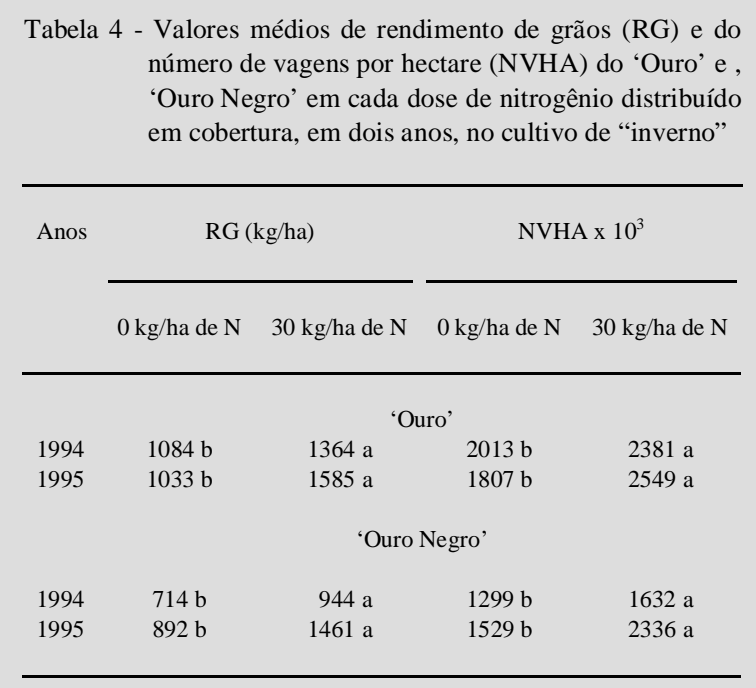

Médias não seguidas pela mesma letra, na linha, diferem significativamente, pelo teste $\mathrm{F}$, a $5 \%$ de probabilidade.

conseqüentemente, no RG, quando expostos à competição com plantas daninhas, em diferentes atrasos na capina. Esses resultados não eram esperados no caso dos cultivares Novo Jalo e Ouro Negro, pois, como é apresentado na figura 1 , a cobertura real de plantas daninhas (CRPD), nesses cultivares, aumentou em função de diferentes atrasos na capina. Verifica-se ainda, que a CRPD nos cultivares Novo Jalo e Ouro, nos dois anos, e no Ouro Negro, no primeiro ano, ajustou-se a um modelo linear. No entanto, no segundo ano, a CRPD do 'Ouro Negro' ajustou-se a um modelo quadrático. Esses diferentes ajustes mostram que a distribuição de plantas daninhas na área experimental foi bastante irregular nos dois anos de plantio.

Não foram observadas diferenças significativas no RG e nos componentes de rendimento do 'Novo Jalo', nos tratamentos em que foram feitas capinas, com ou sem a utilização de nitrogênio em cobertura, em relação à TCC (Tabela 2). Esses resultados mostram que os diferentes atrasos na capina $\left(\mathrm{V}_{3}, \mathrm{~V}_{3}+5, \mathrm{~V}_{3}+10, \mathrm{~V}_{3}+15, \mathrm{~V}_{3}+20\right.$ e $\mathrm{V}_{3}+25$ dias), com ou sem a utilização de nitrogênio em cobertura, não influenciaram significativamente o RG e os seus componentes primários, em relação à TCC. Esse fato pode ser atribuído, também, a outros fatores (doenças e baixa temperatura) que influenciaram negativamente o seu crescimento e desenvolvimento, pois esse cultivar apresentou baixa produtividade em relação aos cultivares Ouro e Ouro Negro, impossibilitando assim de recomendar a melhor época de capina.

Nenhum cultivar apresentou redução significativa do $R G$ no tratamento $\mathrm{V}_{3}+25 \mathrm{~N}_{1}$, em

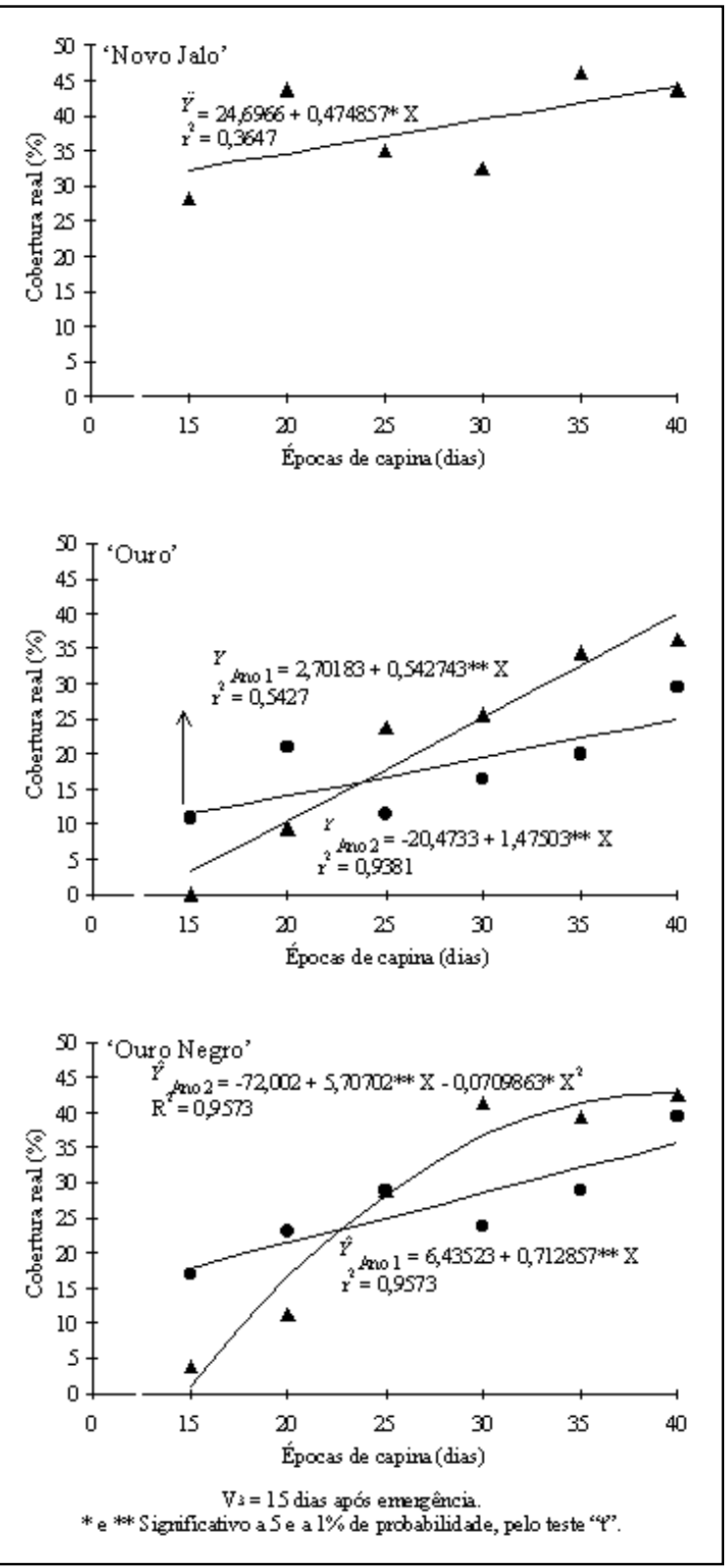

Figura 1 - Estimativa da cobertura real de solo por plantas daninhas $(\hat{Y})$, onde foi cultivado feijão com os cultivares Novo Jalo, Ouro e Ouro Negro, em função de diferentes épocas de capina (X), no cultivo de "inverno".

relação à TCC. Entretanto, nos cultivares Novo Jalo e Ouro, verificou-se tendência de menor RG no tratamento $\mathrm{V}_{3}+25 \mathrm{~N}_{1}$, em relação à TCC. No 'Ouro Negro', o RG no tratamento $\mathrm{V}_{3}+25 \mathrm{~N}_{1}$ foi superior, em relação à $\mathrm{TCC}$, mas os tratamentos $\mathrm{V}_{3} \mathrm{~N}_{1}$ até $\mathrm{V}_{3}$ $+20 \mathrm{~N}_{1}$ apresentaram tendência de menor RG, em relação à TCC (tabela 2). Esses fatos parecem indicar que o nitrogênio aplicado imediatamente após a capina, realizada com atraso de dez dias (tratamento 
$\mathrm{V}_{3}+25 \mathrm{~N}_{1}$ ), em relação ao período total de prevenção da interferência, que é de 30 dias para a cultura do feijão, não foi capaz de proporcionar recuperação total da capacidade produtiva dos feijoeiros.

Os estandes inicial e final não foram influenciados pelo nitrogênio ou pelas épocas de capina, motivo pelo qual os dados não são apresentados. Tal fato pode ser atribuído à aplicação cuidadosa de fertilizantes no sulco de plantio (CARDOSO et al., 1978) e à infestação de plantas daninhas, que alcançou no máximo $41 \%$ de cobertura real, no 'Ouro Negro', no tratamento $\mathrm{V}_{3}+25$ (figura 1).

Em todos os experimentos (cultivares), observaram-se diferenças significativas do peso da massa seca da parte aérea de plantas daninhas monocotiledôneas, dicotiledôneas e total remanescentes (MSM, MSD e MST) na TSC, em relação à TCC, com exceção da MSM no 'Novo Jalo' e no 'Ouro'; da MSD no 'Ouro', no segundo ano, e do 'Ouro Negro, no primeiro ano; e da MST do 'Ouro', no segundo ano (tabela 5).

Nos dois anos, em todos os cultivares, ocorreu predomínio de cobertura real de plantas daninhas dicotiledôneas $(26 \%)$ em relação às plantas daninhas monocotiledôneas (3\%). Esse predomínio

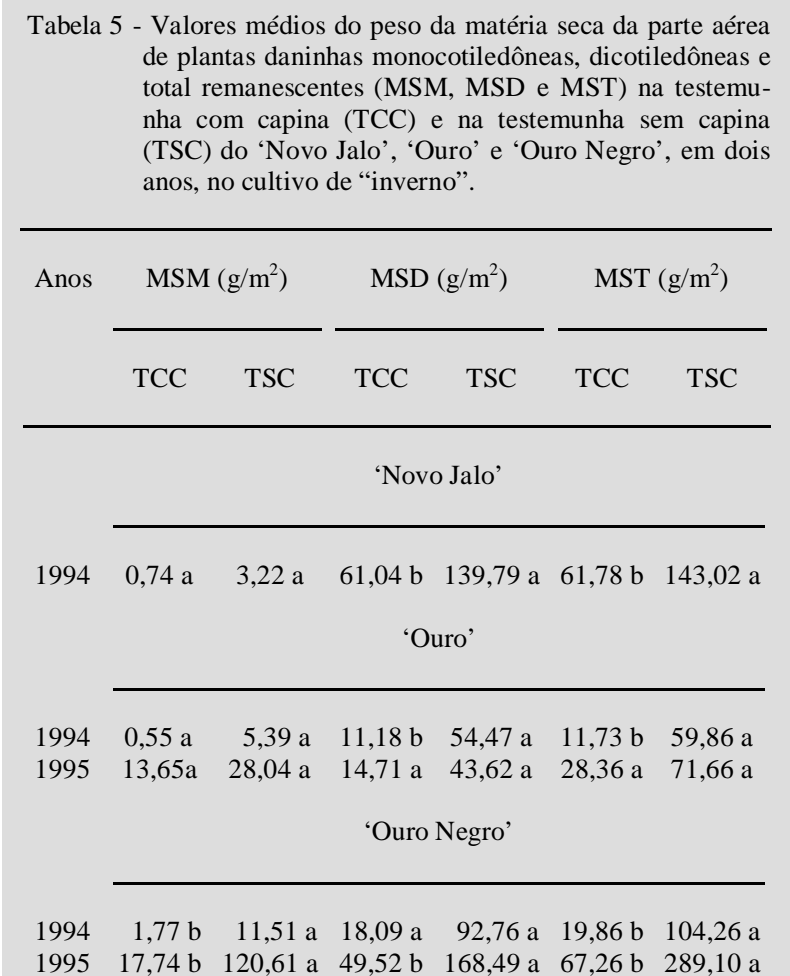
de plantas daninhas monocotiledôneas, dicotiledôneas e total remanescentes (MSM, MSD e MST) na testemunha com capina (TCC) e na testemunha sem capina (TSC) do 'Novo Jalo', 'Ouro' e 'Ouro Negro', em dois anos, no cultivo de "inverno".

Anos $\frac{\operatorname{MSM}\left(\mathrm{g} / \mathrm{m}^{2}\right)}{\operatorname{TCC} \quad \text { TSC }} \frac{\text { MSD }\left(\mathrm{g} / \mathrm{m}^{2}\right)}{\text { TCC }} \frac{}{\text { TSC }} \frac{\text { MST }\left(\mathrm{g} / \mathrm{m}^{2}\right)}{\text { TCC } \quad \text { TSC }}$

'Novo Jalo'

$1994 \quad 0,74$ a $\quad 3,22$ a $\quad 61,04$ b $\quad 139,79$ a $\quad 61,78$ b $\quad 143,02$ a

'Ouro'

$\begin{array}{llllllll}1994 & 0,55 \mathrm{a} & 5,39 \mathrm{a} & 11,18 \mathrm{~b} & 54,47 \mathrm{a} & 11,73 \mathrm{~b} & 59,86 \mathrm{a}\end{array}$

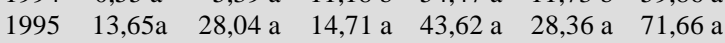

'Ouro Negro'

$1994 \quad 1,77$ b 11,51 a $\quad 18,09$ a $\quad 92,76$ a $\quad 19,86$ b 104,26 a 199517,74 b 120,61 a $\quad 49,52$ b $\quad 168,49$ a $\quad 67,26$ b 289,10 a

Médias não seguidas pela mesma letra, na linha, em cada variável diferem significativamente, pelo teste $\mathrm{F}$, a $5 \%$ de probabilidade. também foi observado por ocasião da colheita, com maior peso de massa seca de plantas daninhas dicotiledôneas (Tabela 5). Segundo DEUBER (1992) e FERREIRA et al. (1994), as espécies de plantas daninhas anuais de inverno pertencem à classe dicotiledonea, ocorrendo bem poucas espécies da classe monocotiledônea nos períodos mais frios. As espécies de gramíneas perenes são exceções, sobrevivendo no período frio, com redução do seu crescimento ou entrando em repouso vegetativo.

\section{CONCLUSÃO}

A competição com plantas daninhas reduz a produção de cultivares de feijão e, a execução da capina até dez dias após o período total de prevenção de interferência, com posterior adubação nitrogenada em cobertura, não proporcionou recuperação da capacidade produtiva dos feijoeiros.

\section{REFERÊNCIAS BIBLIOGRÁFICAS}

AMANE, M.I.V. Resposta de cultivares de feijão (Phaseolus vulgaris $\mathrm{L}$.) às adubações nitrogenada e molíbdica. Viçosa, MG, 70p. Tese (Mestrado em Fitotecnia) - Curso de Pósgraduação em Fitotecnia, Universidade Federal de Viçosa, 1994.

BANZATTO, D.A., KRONKA, S.N. Experimentação agrícola. Jaboticabal: FUNEP, 1989. 247 p

CALVACHE, M., REICHARDT, K., SILVA, J.C.A., $\boldsymbol{e} \boldsymbol{t} \boldsymbol{a l}$ Adubação nitrogenada no feijão sob estresse de água, Viçosa, MG, 1995. In: CONGRESSO BRASILEIRO DE CIÊNCIA DO SOLO, 25, 1995. Viçosa, MG. Resumos expandidos... Viçosa, MG: SBCS/UFV, 1995. v. 3. p. 649-651.

CARDOSO, A.A., FONTES, L.A.N., VIEIRA, C. Efeito de fontes e doses de adubo nitrogenado sobre a cultura do feijão (Phaseolus vulgaris L.). Revista Ceres, Viçosa, v. 25, n. 139, p. 292-295, 1978.

COMISSÃO DE FERTILIDADE DO SOLO DO ESTADO DE MINAS GERAIS. Recomendações para o uso de corretivos e fertilizantes em Minas Gerais. $4^{\mathrm{a}}$ Aproximação. Lavras, 1989. $159 \mathrm{p}$.

CRUZ, C.D., REGAZZI, A.J. Modelos biométricos aplicados ao melhoramento genético. Viçosa, MG: UFV, 1994. 390 p.

DEUBER, R. Ciência das plantas daninhas: fundamentos. Jaboticabal: FUNEP, 1992. 43 p.

DINIZ, A.R., ANDRADE, M.J.B., CARVLHO, J.G., et al. Resposta da cultura do feijão (Phaseolus vulgaris L.) à aplicação de nitrogênio (cobertura e semeadura) e de molibdênio foliar. In: CONGRESSO BRASILEIRO DE CIÊNCIA DO SOLO, 25, 1995. Viçosa, MG. Resumos expandidos... Viçosa, MG: SBCS/UFV, 1995. v. 3, p. 1125-1127.

FERREIRA, L.R., FERREIRA, F.A., SIVA, J.F. Manejo integrado de plantas daninhas na cultura do feijão de outonoinverno. Informe Agropecuário, Belo Horizonte, v. 17, n. 178, p. 38-42, 1994. 
INSTITUTO BRASILEIRO DE GEOGRAFIA E ESTATÍSTICA. Levantamento Sistemático da Produção Agrícola, Brasília, DF, v. 7, n. 5, p. 1-51, 1995.

MARSCHNER, H. Mineral nutrition of higher plants. London: Academic Press, 1986. 674 p.

MOURA, P.A., PAIVA, B.M., RESENDE, L.M.A. Aspectos econômicos da cultura do feijão. Informe Agropecuário,Belo Horizonte, MG, n.17, v. 178, p. 67-72, 1994

NIETO, J.H., BRONDO, M.A., GONZALEZ, J.T. Critical periods of the crop growth cicle for competition from weeds. Pest Articles and News Summaries. Section C, v. 14, n. 2 p. 159-166, 1968.
PITELLI, R.A., DURIGAN, J.C. Terminologia para períodos de controle e de convivência das plantas daninhas em culturas anuais e bianuais. In: CONGRESSO BRASILEIRO DE HERBICIDAS E PLANTAS DANINHAS, 15, 1984. Belo Horizonte, MG,. Resumos... Piracicaba, SP: AUGEGRAF, 1984. p. 37.

PITELLI, R.A. Interferência de plantas daninhas em culturas agrícolas. Informe Agropecuário, Belo Horizonte, MG, v. 11, n. 129 , p. 16-27, 1985.

VIEIRA, C. Período crítico de competição entre ervas daninhas e a cultura do feijão (Phaseolus vulgaris L.). Revista Ceres, Viçosa, MG, v. 17, n. 94, p. 354-367, 1970.

Ciência Rural, v. 29, n. 2, 1999. 